\title{
Stabilization of Soft Soil with Cement and Palm Kernel Shell Ash Admixture
}

\author{
Yulian Firmana Arifin ${ }^{1, *}$ and Gazali Rahman $^{1}$ \\ ${ }^{1}$ Engineering Faculty, Universitas Lambung Mangkurat
}

\begin{abstract}
This paper focuses the results of the improvement in shear strength parameters and CBR of soft clay when stabilized with cement and cement-Palm Kernel Shell Ash (PKSA). Different combinations of soilcement and soil-cement-PKSA mixtures are prepared with the addition of cement and PKSA in the range of $2-10 \%$ by weight of soil. Series of tests including compaction, UCT, and CBR tests were performed. The influence of curing time is also studied on CBR and undrained strength property of various sample combinations. Results indicate that the addition of PKSA to the soil-cement mixtures increases the CBR. The percentage of optimum PKSA content in the mix for soil with $10 \%$ cement is $2 \%$. The effect of time on clay, cement, and PKSA mixture is significant, i.e., an average of $0.5 \%$ per day.
\end{abstract}

\section{Introduction}

Soil stabilization is a method of altering soil behavior to improve its performance to be used in construction. Cement is one of the most commonly used materials for soil stabilization. Records from the literature show that cement is an effective stabilizer in the improvement of the strength properties not only coarse-grained soil [1], [2], [3], [4] but also fine-grained soil [5], [6], [7].

It is reported that the amount of cement needed for soil stabilization depends on the type of soils [8]. The typical range of cement requirement for coarse-grained soils is between 3$11 \%$ and for low plasticity of clay or silt soils of $7-12 \%$. The required cement increases up to $16 \%$ for high plastic clays [8].

Shear strength of cement stabilized soil is also influenced by curing time depending on types of soils [8]. The strength increase of granular material is higher than that of clayey or silty soils. It is also reported that the increase in slope of silt (the exponent on time) between 6 and 10 percent cement content is more significant than the change from 10 to 14 percent cement [5]. The result repeals that above a minimum content of cement the hardening is not dependent on the change in the gel but reflects increased bonding to the mineral crystals. Besides influencing of stress-strain behavior, the strain at failure also decreases by increasing curing time [7].

A single stabilizing agent may not improve significantly in the required properties of the soils [7-8]. By adding fly ash, lime, or both, to Portland cement, the durability of freezing

* Corresponding author: y.arifin@ulm.ac.id 
and thawing of stabilized soil increases and permeability of the mixture decreases significantly [9]. Replacing a portion of cement with fly ash reduces overall shrinkage [10]. In some cases, combining two stabilizers has not the only potential to improve the strength and stability of subgrade but also ease of implementation in the field. Addition of lime or fly ash may reduce the excess moisture content of soil before using cement [8].

Palm Kernel shell ash (PKSA) has also been used in soil stabilization [11-12]. Based on the chemical composition and pozzolanicity test, PKSA is pozzolanic [13]. Pozzolans are usually used as additives to Portland cement mixtures to increase the long-term strength and other material properties. In some cases, the use of pozzolans reduces the material cost.

This paper, therefore, focuses on analyzing the effect of the amount of cement, PKSA and the curing time on bearing capacity and the strength parameters of a soft soil through unconfined compression (UCT) and soaked California Bearing Ratio (CBR) tests.

\section{The material used and methods}

The soft soil used in this study is a soft clay obtained from Bukit Rawi village in District of Pulang Pisau, Central Kalimantan. The soil has low bearing capacity analyzed by CBR and UCT data [2]. The engineering properties of the soil are summarized in Table 1. The tests were performed based on ASTM standards [14]. The chemical compounds of clay shown in Table 2 were determined using XRF method. Based on Tabel 1, soil used classifies as high plastic clay $(\mathrm{CH})$ based on USCS method. The chemical compounds of soil sample are mainly $\mathrm{Al}$ and $\mathrm{Si}$ which are common compounds in soil.

Cement used is ordinary Portland cement Type I which contains dominant hydroxide of $\mathrm{CaO}, \mathrm{SiO} 2, \mathrm{Al} 2 \mathrm{O} 3$ dan $\mathrm{Fe} 2 \mathrm{O} 3$. The PKSA that is a by-product of the combustion of palm kernel shells was obtained from a palm oil factory in Sampit, East Kotawaringin District, Central Kalimantan. The chemical compositions of PKSA are summarized in Table 3.

The compositions of soil-cement prepared were $98 \%-2 \%, 94 \%-6 \%$, and $90 \%-10 \%$ to obtain the optimum moisture content, dry density, and optimum cement content from soaked CBR and UCT tests. Proctor compaction method [14] was performed to obtain the optimum moisture content and dry density for the respective mixture. UCT and CBR tests were performed to the soil at the optimum moisture content condition. The result was analyzed to obtain optimum cement content that to be used for mixtures of soil-cementPKSA. Percentages of 2, 6, and 10 were used in the mixes. Again, the soaked CBR test was performed. To investigate the effect of time, the specimens have been cured by covering them with plastic wrap for 1,7 , and 14 days, respectively.

Table 1. Engineering properties of clay from Bukit Rawi Village

\begin{tabular}{|cc|c|}
\hline Soil Parameter & & value \\
\hline Water content & $\%$ & 34,23 \\
\hline Specific gravity & & 2,52 \\
\hline Grain size & $\%$ & 0,05 \\
\hline gravel $(>2 \mathrm{~mm})$ & $\%$ & 1,31 \\
\hline Coarse sand $(0.6-2.0 \mathrm{~mm})$ & $\%$ & 1,59 \\
\hline Medium sand $(0.2-0.6 \mathrm{~mm})$ & $\%$ & 1,67 \\
\hline Fine sand $(0.05-0.2 \mathrm{~mm})$ & $\%$ & 17,30 \\
\hline Silt $(0.002-0.05)$ & $\%$ & 78,08 \\
\hline Clay $(<0.002 \mathrm{~mm})$ & & \\
\hline Atterberg limits & $\%$ \\
\hline
\end{tabular}




\begin{tabular}{|cc|c|}
\hline Liquid limits & $\%$ & 72,78 \\
\hline Plastic limits & $\%$ & 23,47 \\
\hline Plasticity index & $\%$ & 49,31 \\
\hline Soil type (USCS) & & $\mathrm{CH}$ \\
\hline Proctor compaction standard & & \\
\hline Dry volumetric weight & $\mathrm{g} / \mathrm{cm}^{3}$ & 1,23 \\
\hline Optimum moisture content & $\%$ & 34,35 \\
\hline CBR & $\%$ & 3,8 \\
\hline Unconfined compression test $\left(\mathrm{q}_{\mathrm{u}}\right)$ & $\mathrm{kg} / \mathrm{cm}^{2}$ & 0,396 \\
\hline
\end{tabular}

Table 2. Chemical compound of soil

\begin{tabular}{|c|c|c|c|c|c|c|c|c|c|}
\hline Compound & $\mathbf{A l}$ & $\mathbf{S i}$ & $\mathbf{P}$ & $\mathbf{K}$ & $\mathbf{C a}$ & $\mathbf{T i}$ & $\mathbf{F e}$ & $\mathbf{C u}$ & $\mathbf{Z n}$ \\
\hline $\mathbf{( \% )}$ & 30,9 & 51,3 & 0,95 & 2,75 & 0,76 & 5,66 & 6,81 & 0,13 & 0,1 \\
\hline
\end{tabular}

Table 3. Chemical composition of PKSA

\begin{tabular}{|c|c|c|c|c|c|c|c|c|c|c|}
\hline Compound & SiO2 & K2O & Al2O3 & CaO & Fe2O3 & P2O5 & TiO2 & CuO & ZnO & Source \\
\hline$(\%)$ & 42,2 & 5,80 & - & 4,99 & 34,5 & 5,3 & 0,67 & 0,42 & 3,99 & $1)$ \\
\hline$(\%)$ & 54,8 & 6,5 & 11,40 & 8,79 & 0,36 & - & - & - & - & $2)$ \\
\hline$(\%)$ & 28,59 & 0,02 & 22,44 & 0,04 & 9 & - & - & - & - & $3)$ \\
\hline
\end{tabular}

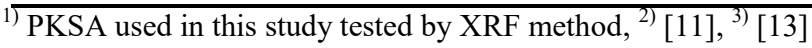

\section{Results and discussions}

The compaction test was performed to obtain the optimum moisture content (OMC) corresponding to its maximum dry density. Figure 1(a) and (b) show the effects of cement content on the dry density and OMC, respectively. The optimum water content of $34,35 \%$ corresponding to the dry density of $1,23 \mathrm{gr} / \mathrm{cm}^{3}$ was obtained for the sample with zero cement amounts. These high OMC and low dry density repeal that the soil consists of more clay that commonly has low shear strength. The effect of cement content on the dry density of samples is shown in Figure 1(a). As shown in the figure, the dry density of samples is relatively constant at the cement content from 0 to $6 \%$. The dry density increases up to 1,25 $\mathrm{gr} / \mathrm{cm}^{3}$ at the cement content of $10 \%$. Replacement of soil by the heavy weight of cement is expected to increase the dry density. However, rise in OMC due to the presence of cement in the range of $2-6 \%$ cement results in decreasing dry density. Beyond $6 \%$, OMC decreases due to reducing of porous voids filled by cement. This condition results in increasing the dry density.

Figure 2(a) demonstrates typical load development in CBR test for samples in the range of $2-10 \%$ cement. At a specific penetration, increase in cement content results in increasing load significantly. The figure also indicates that the slopes of load development at penetration less than 0.2 inch increase by increasing cement content.

Figure 2(b) shows the effect of curing time on the load development of soil stabilized with $6 \%$ cement as an example. At a specific penetration, longer curing time results in increasing load. The slopes of load development at penetration less than 0,2 inch are similar indicating less effect of curing time on load development. 


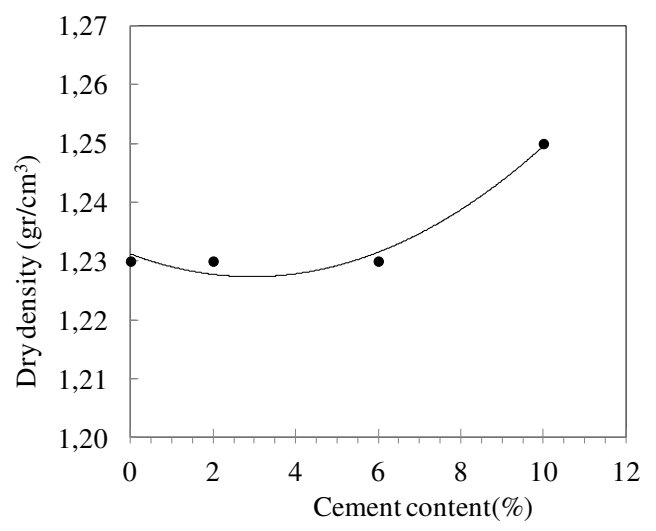

(a)

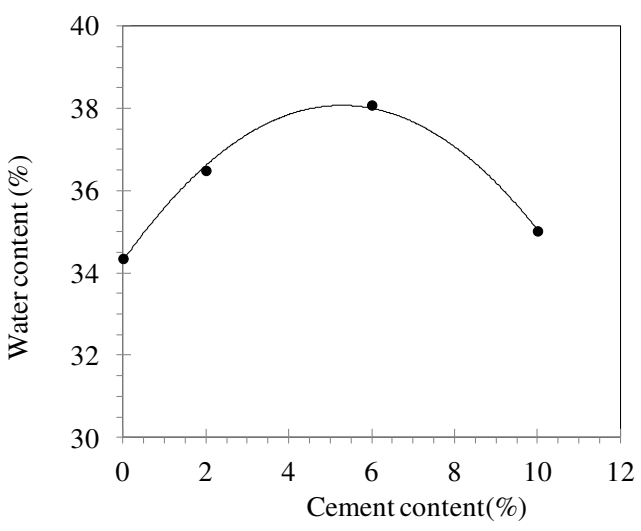

(b)

Fig. 1. Proctor compaction standard test (a) compaction curves, and (b) dry density versus cement content

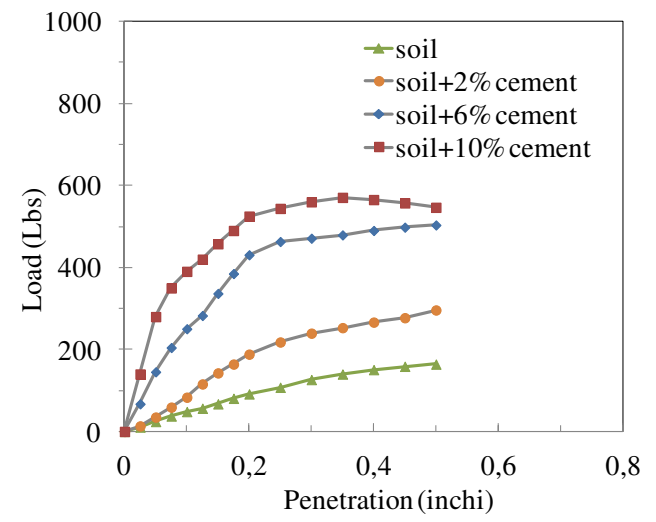

(a)

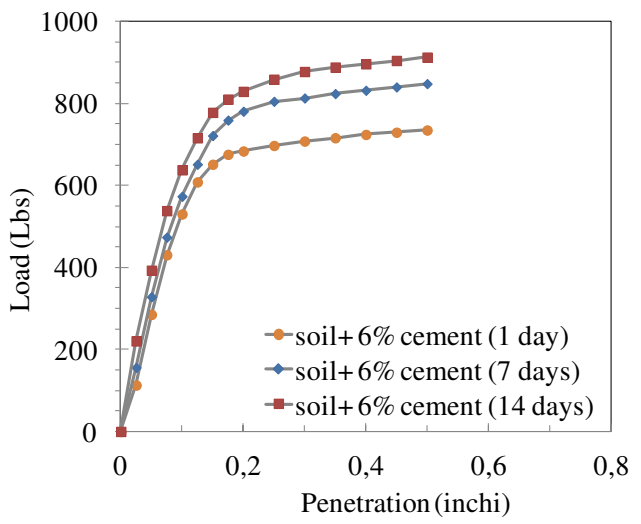

(b)

Fig. 2. Typical load development in the CBR tests (a) load versus penetration of samples with different cement content, (b) load versus penetration of samples cured at the different curing time

CBR test results as a function of cement content and curing time are presented in Figures 3(a) and 3(b), respectively. From Figure 3(a), the trends are seen that the CBR increases by increasing the cement content. The curves of CBR as a function of cement content for different curing time are also presented in the figure. The curves are seen close to each other indicating less effect of curing time on CBR of the soil-cement mixtures investigated in this study. Figure3(b) shows more clearly the influence of curing time on soil and cement mixtures. The average of CBR increment is $0.1 \%$ per day. In general, it can be concluded that the curing time effect on CBR up to 14 days is not significant.

The UCT cylindrical samples of $38 \mathrm{~mm} \times 76 \mathrm{~mm}$ size were molded at its maximum dry density and OMC of each soil composition. A series of UCT tests were performed according to ASTM standard [14]. The experiment was repeated in thrice for each test sample to obtain the average maximum strength value. Figures 4(a) and 4(b) show typical pressure applied as a function of strain for soil with different cement content and sample with $10 \%$ cement cured at the different period (i.e., 1, 7, and 14 days), respectively. In general, pressure increases by increasing strain and reaches a peak at a particular strain. The top or maximum pressure is higher for the sample with higher cement content in the 
mixture. In connection with that, the strain at maximum pressure decreases by increasing cement content [7].

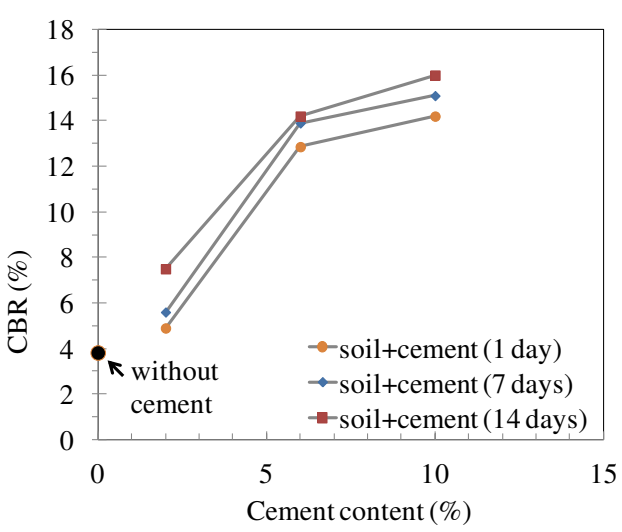

(a)

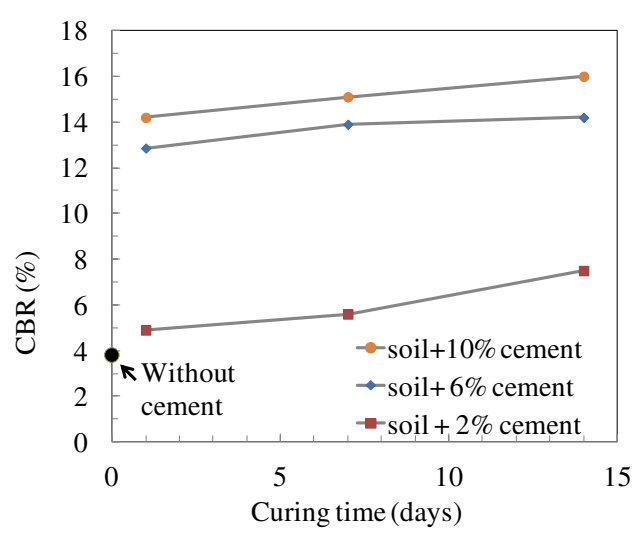

(b)

Fig. 3. CBR result (a) as a function of cement content, and (b) as a function of curing time

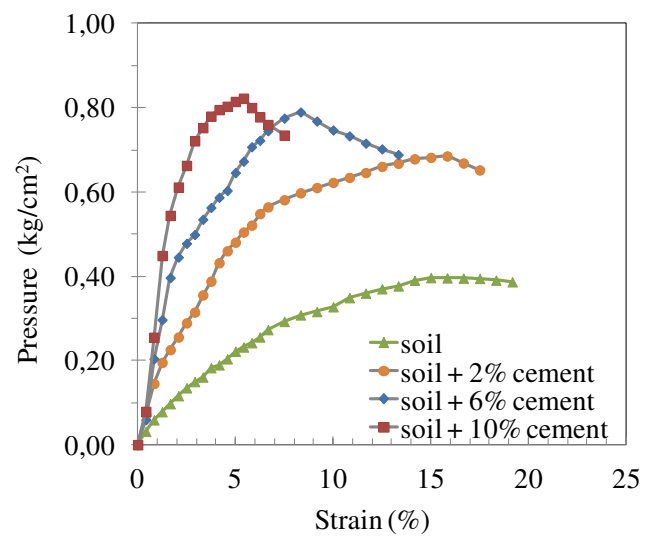

(a)

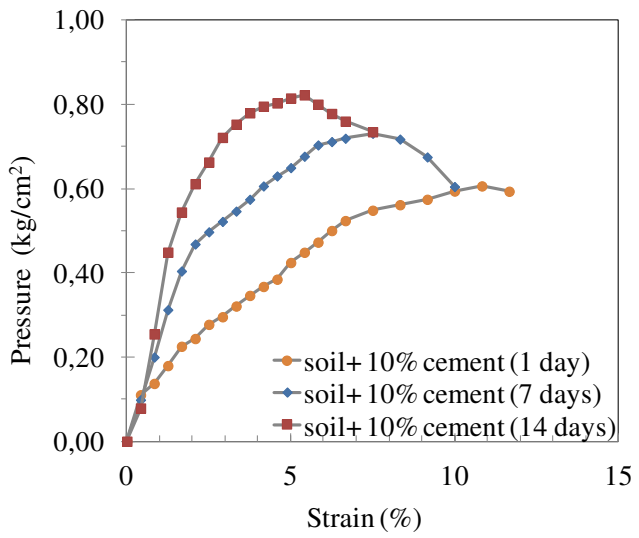

(b)

Fig. 4. Unconfined compression test results (a) samples for different cement content, and (b) samples for the different curing time at the same cement content

The unconfined compression strength (qu) of a sample can be obtained from the curves in Figure 4 by recording the maximum pressure at the respective curve. In engineering design, a parameter of undrained shear strength or undrained cohesion $\left(\mathrm{c}_{\mathrm{u}}\right)$ is used and determined from $c_{u}=1 / 2 q_{u}[15]$. Figures 5(a) and 5(b) show the undrained shear strength of soil-cement mixtures as a function of cement content and curing time, respectively. As shown in Figure 5(a), the presence of cement influences cu in the range of 2-6\% cement content. Beyond $6 \%$, the cu is relatively constant with increasing cement. Similar to CBR result, time effect on $\mathrm{cu}$ is also not significant. In average, the increment of $c_{\mathrm{u}}$ is $0,006-$ $0,008 \mathrm{~kg} / \mathrm{cm}^{2}$ per day.

A cement content of $10 \%$ was selected to be used for sample mix with PKSA. Only, soaked CBR test was performed in this admixture. PKSA content of 2,6 , and $10 \%$ was used, and the results of typical load versus penetration are presented in Figure 6. As shown in Figure 6(a), the load development of samples with PKSA content in the range $2-10 \%$ is similar. The PKSA demonstrates a significant influence of curing time as shown in Figure 6(a). The figure shows the difference of load development curves of sample cured in 7 and 14 days. 


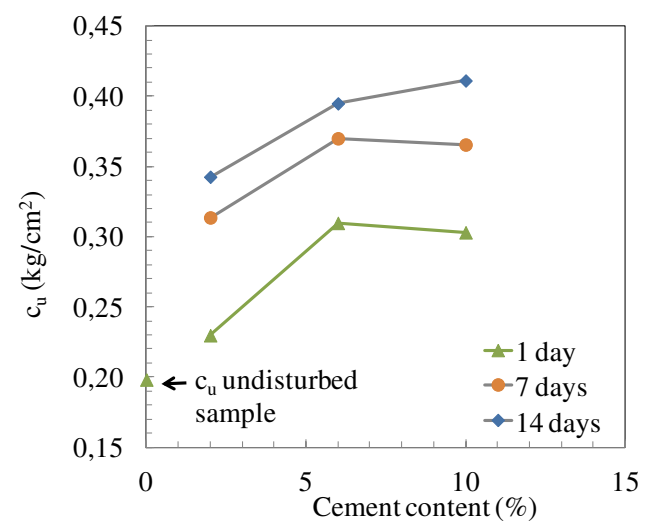

(a)

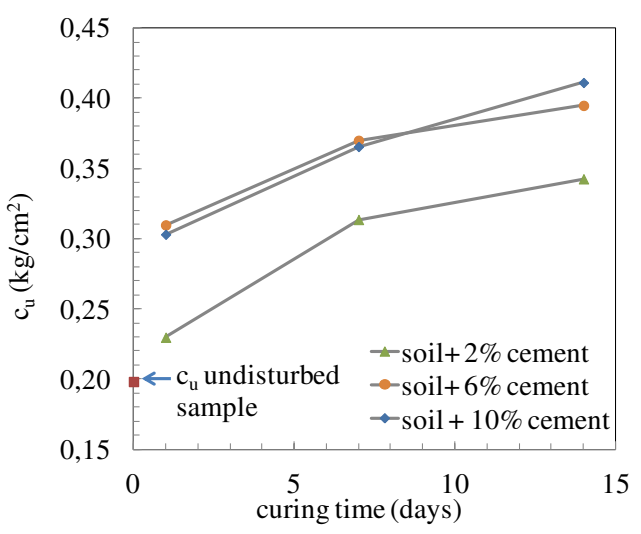

(b)

Fig. 5. Undrained shear strength as a function of (a) cement content, and (b) curing time

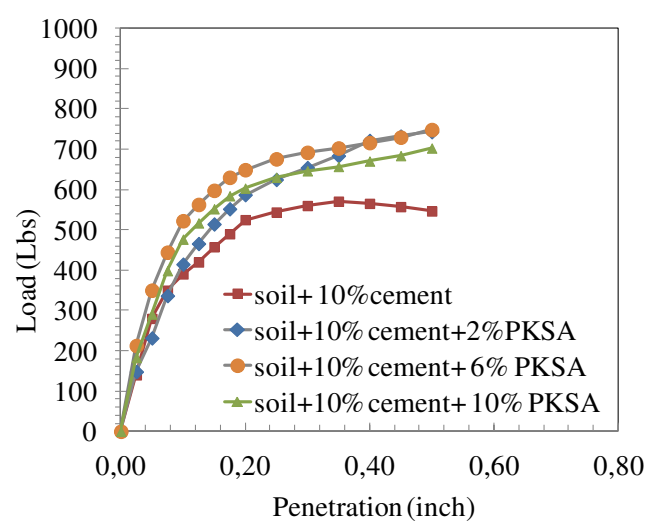

(a)

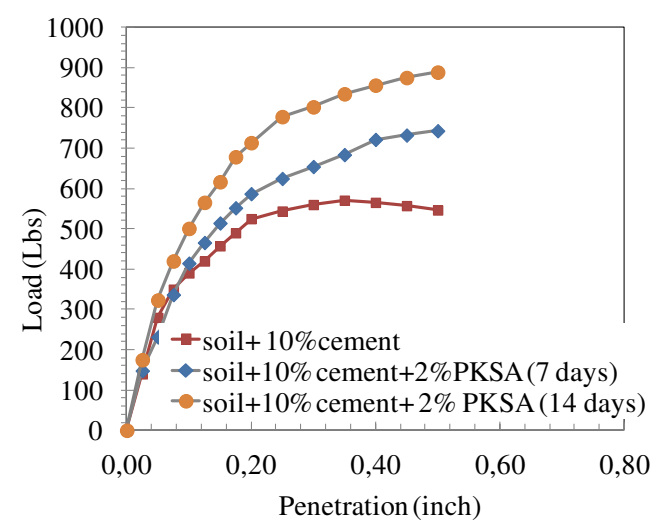

(b)

Fig. 6. Typical load versus penetration of sample obtained from CBR tests (a) considering PKSA content effect, (b) considering curing time effect.

Effects of PKSA content and curing time on the CBR of the mixtures are summarized in Figure 7. As shown in the figure, CBR is relative constant by increasing PKSA content. For the sample with $2 \%$ PKSA, the CBR increases from 16 to $20.5 \%$ after curing for seven days. It can be concluded that, in the range of $2-10 \%$ PKSA in the mixture, curing time is more significant effect than its percentage.

\section{Conclusions}

The result of the stabilization of soft clay using cement and PKSA has been described and discussed. The addition of cement results in an increase in the CBR (submerged condition) that is more than twice of CBR parent soil at a cement content of more than $6 \%$. The curing time of mixed clay and cement samples (without PKSA) in the range of 1-14 days increases the average CBR of $0.1 \%$ per day. The effect of curing on the CBR of soil-cement mixtures is not significant. Similar to CBR, the $c_{u}$ is higher with the addition of cement up to $6 \%$. The effect of 1-14 day curing time on $c_{u}$ is also not significant. The average increase in $c_{u}$ is between $0.006-0.008 \mathrm{~kg} / \mathrm{cm}^{2}$ per day. 


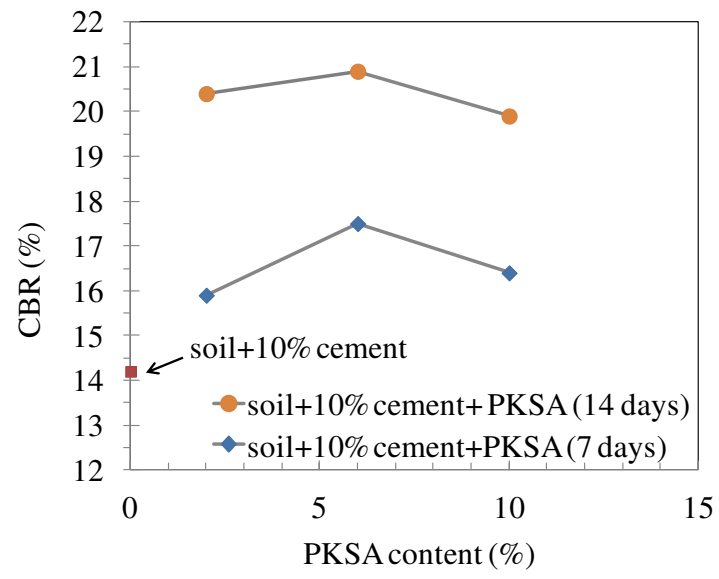

Fig. 7. PKSA content and curing time effects on the CBR of sample

The addition of PKSA to the soil-cement mixtures increases the CBR. The percentage of optimum PKSA content in the mix for soil with $10 \%$ cement is $2 \%$. The effect of time on clay, cement, and PKSA mixture is significant, i.e., an average of $0.5 \%$ per day.

\section{References}

1. Shooshpasha, R.A. Shirvani, Effect of cement stabilization on geotechnical properties of sandy soils Geomechanics and Engineering, 8, 1, pp. 17-31 (2015)

2. A. Muda, Comparison of CBR and UCS of sand and cement stabilized soil (in Bahasa), Anterior Jurnal 16, 1, pp 84-89 (2016)

3. A. Pandey, A. Rabbani, Soil stabilization using Cement, Int. J. of Civ. Eng. and Tech., 8, 6, pp.316-322 (2017)

4. D.R. Biswal, U.C. Sahoo, S.R. Dash, Strength and Stiffness Studies of Cement Stabilized Granular Lateritic Soil, In W. Frikha et al. (eds.), Soil Testing, Soil Stability and Ground Improvement, Sustainable Civil Infrastructures, pp 320-335 (2018)

5. R.L. Handy, Cementation of Soil Minerals with Portland Cement or Alkalis, Highway Research Board Bulletin, Issue No. 198, Highway Research Board (1958)

6. C. Teerawattanasuk, P. Voottipruex, Influence of Clay and Silt Proportions on CementTreated Fine-Grained Soil, J. of Mat. in Civ. Eng. 26, 3, pp. 420 - 428 (2014)

7. A.A. Amadi, A.S. Osu, Effect of Curing Time on Strength Development in Black Cotton Soil-Quarry Fines Composite Stabilized with Cement Kiln Dust (CKD), Journal of King Saud University, Engineering Science (2016)

8. American Concrete Institute Committee 230, Report on Soil Cement, ACI 230.1R-09 (2009)

9. C.J. Moretti, Development of Fly Ash Liners for Waste Disposal Sites, Proceedings, 8th International Coal Ash Utilization Symposium, Report No. CS-5362, American Coal Ash Association, Washington, V.2, Palo Alto, CA, Oct. (1987)

10. K.P. George, Minimizing Cracking in Cement-Treated Materials for Improved Performance, RD123 Portland Cement Association, Skokie, IL (2002)

11. E.A. Adeyemi, O.A. Joseph, Comparative Analysis of Ekiti State Soil Stabilized with Different Additives. Asian J. of Scien and Tech. 06, 12, pp. 2054-2058 ( 2015) 
12. E.S. Nnochiri, O.M. Ogundipe, O.E. Oluwatuyi, Effects Of Palm Kernel Shell Ash on Lime-Stabilized Lateritic Soil 25, 3, 1 - 7 (2017)

13. M.C. Ogbodo, Palm Kernel Shell Ash as A Soil Stabilizing Agent and Its Optimum Calcine Temperature, IJARP, 1, 4, 191-193 (2017)

14. ASTM. Annual Book of Standards. 04.08 and 04.09, Soil and rock, ASTM International. West Conshohocken. PA. (1997)

15. B.M. Das, Soil Mechanics Laboratory Manual, Sixth Edition, Oxford University Press (2002) 